\title{
HUBUNGAN ANTARA KOORDINASI MATA-TANGAN, PERSEPSI \\ KINESTETIK DAN KEKUATAN OTOT PERUT DENGAN KEMAMPUAN \\ SHORT SER VICE DALAM PERMAINAN BULUTANGKIS PADA PEMAIN \\ PUTRA USIA 14-15 TAHUN PB NATURA PRAMBANAN KLATEN TAHUN \\ 2019
}

\author{
Iwan Arya Kusuma \\ Universitas Tunas Pembangunan Surakarta
}

\begin{abstract}
ABSTRAK
Tujuan dari penelitian ini adalah untuk mengetahui: (1) Hubungan antara Koordinasi Mata-Tangan Dengan Kemampuan Short Service Dalam Permainan Bulutangkis Pada Pemain Putra Usia 14-15 Tahun PB Natura Prambanan Klaten Tahun 2019. (2) Hubungan antara Persepsi Kinestetik Dengan Kemampuan Short Service Dalam Permainan Bulutangkis Pada Pemain Putra Usia 14-15 Tahun Pb Natura Prambanan Klaten Tahun 2019. (3) Hubungan antara Kekuatan Otot Perut Dengan Kemampuan Short Service Dalam Permainan Bulutangkis Pada Pemain Putra Usia 1415 Tahun Pb Natura Prambanan Klaten Tahun 2019. (4) Hubungan antara Koordinasi Mata-Tangan, Persepsi Kinestetik Dan Kekuatan Otot Perut Dengan Kemampuan Short Service Dalam Permainan Bulutangkis Pada Pemain Putra Usia 14-15 Tahun PB Natura Prambanan Klaten Tahun 2019.

Dalam penelitian ini variabel bebas disebut juga sebagai prediktor dan variabel terikat yang disebut juga sebagai kriterium. Teknik pengumpulan data dalam penelitian ini adalah menggunakan teknik tes dan pengukuran. Adapun jenis tes yang digunakan adalah: (1). Untuk mengukur koordinasi mata-tangan dengan lempar tangkap bola tenis dari Ismaryati (2006: 54-55). (2) Tes dan pengukuran persepsi kinestetik dengan vertical linier space test dari Barry L. Johnson \& Jack K. Nelson (1970:188-190). (3) Tes dan pengukuran kekuatan otot perut dengan sit up (Ismaryati, 2008: 119-120). (4) Kemampuan Short Service diukur dengan Tes Servis Pendek (Sapta Kunta Purnama, 2010 : 31). Petunjuk peleksanaan masing-masing tes terlampir.

Berdasarkan analisis data dan pengujian hipotesis yang telah dilakukan, maka simpulan yang dapat diperoleh adalah: (1) Ada hubungan yang signifikan antara Koordinasi Mata-Tangan dengan Kemampuan Short Service, $r_{\text {hitung }}=0,426>r_{\text {tabel }} \%=$ 0,361. (2) Ada hubungan yang signifikan antara Persepsi kinestetik dengan Kemampuan Short Service, $\mathrm{r}_{\text {hitung }}=0,414>\mathrm{r}_{\text {tabel }} \%=0,361$. (3) Ada hubungan yang signifikan antara Kekuatan Otot Perut dengan Kemampuan Short Service, $r_{\text {hitung }}=0,458>r_{\text {tabel }} \%=$ 0,361. (4) Ada hubungan yang signifikan antara Koordinasi Mata-Tangan, Persepsi kinestetik dan Kekuatan Otot Perut dengan Kemampuan Short Service, $\mathrm{R}_{\mathrm{y}(123)}^{2}$ sebesar $0.452>\mathrm{r}_{\text {tabel5 }} \%$ pada taraf signifikansi $5 \%$ sebesar 0.361 dan $\mathrm{F}_{0}$ sebesar 7,1725> $\mathrm{f}_{\text {tabel }}$ pada taraf signifikansi 5\% sebesar 2,89.
\end{abstract}

Kata Kunci : Koordinasi Mata-Tangan, Persepsi Kinestetik, Kekuatan Otot Perut, Kemampuan Short Service 


\section{PENDAHULUAN}

Banyak orang melakukan olahraga bulutangkis dengan berbagai macam tujuan, diantaranya untuk rekreasidan hiburan, menjaga kebugaran dan kesehatan sampai untuk tujuan olahragaprestasi. Sebagai cabang olahraga prestasi, bulutangkis termasuk olahragakompetitif yang memerlukan gerakan eksplosif, banyak gerakan berlari, meloncatuntuk smash, refleks, kecepatan merubah arah dan juga membutuhkan koordinasimata-tangan yang baik. Permainan bulutangkis adalah cabang olahraga yang banyak digemari oleh masyarakat di seluruh dunia, tidak terkecuali di Indonesia. Hal ini dapatdilihat dengan banyaknya masyarakat yang ikut serta dalam setiap kegiatanolahraga bulutangkis yang diselenggarakan, baik dalam bentuk pertandingantingkat RT hingga tingkat dunia, seperti Thomas dan Uber Cup atau Olimpiade.Olahraga bulutangkis dapat dimainkan mulai dari anak-anak hingga orang dewasadan dapat dilakukan di dalam maupun di luar ruangan..

Olahraga prestasi menitik beratkan pada pencapaian prestasi dalam cabang olahraga yang ditekuni. Prestasi olahraga tidak dapat diperoleh dalamwaktu yang singkat atau waktu yang pendek dan jalan pintas. Prestasi olahragadihasilkan melalui program pembinaan dan pengembangan, secara bertahap danberkesinambungan. Dalam meningkatkan prestasi olahraga bukan hal yangmudah, namun diperlukan pembinaan dan pengembangan ilmu pengetahuan danteknologi (IPTEK) keolahragaan, sumberdaya manusia (SDM), dan sumberdayaalam (SDA) secara optimal.

Olahraga bulutangkis sama dengan olahraga permainan yang lain,dimana seseorang untuk dapat bermain harus menguasai terlebih dahulu teknik-teknikdasar permainan yang dipergunakan. Teknik-teknik dasar tersebutmempunyai karakteristik yang sesuai dengan bentuk permainannya. Dalampermainan bulutangkis teknik-teknik dasar yang utama adalah smash, hal inisesuai dengan pendapat dari Pudjianto dan kawan-kawan (1978: 17) adalah, "Lob,Smash, Dropshot, Drive, Pukulan Service, Return Service".Seiring dengan kondisi pembinaan atlet berprestasi haruslah dimulai dariisntitusi dimana pembinaan jasmani diberikan secara teratur. Kegiatan pembinaan pemain muda yang diberikan di PB Natura Pambanan Klaten memberikan ruang yang besar bagi terciptanya kegiatan olahraga yang kondusifmengarah pada perkembangan olahraga prestasi secara maksimal, dimana selamaini agak terabaikan dibanding dengan 
HUBUNGAN ANTARA KOORDINASI MATA-TANGAN, PERSEPSI KINESTETIK DAN KEKUATAN

OTOT PERUT DENGAN KEMAMPUAN SHORT SERVICE DALAM PERMAINAN BULUTANGKIS

PADA PEMAIN PUTRA USIA 14-15 TAHUN PB NATURA PRAMBANAN KLATEN TAHUN 2019

(Iwan Arya Kusuma)

klub-klub diluar institusi formal ini. Pembinaan pemain bulutangkis PB Natura Pambanan Klaten adalah salah satu Persatuan Bulutangkis yang memiliki prestasi pemain yang baik, bulutangkis mencoba untuk mengembangkan prestasi bulutangkisdengan memberikan pelatihan yang intensif dan fasilitas penunjang yang memadaiserta mendatangkan pelatih guna pembinaan olahraga prestasi ini dengan tujuan untuk mendapatkan atlet-atlet yang mempunyai prestasi yang maksimal yang merupakan hasil pembinaan di Klaten pada khususnya.

Dalam bulutangkis ada beberapa latihan teknik yang harus dikuasaidiantaranya: teknik memegang raket, teknik memukul shutle kok, teknik penguasaankerja kaki. Latihan teknik ini diberikan setelah pemberian latihan fisik. Pada teknik memukul dibedakan menjadi pukulan overhead dapat berupa smash, lob,drop shot, netting, pukulan side arm dapat berupa drive drop, drive clear, pukulanunder arm dapat berupa under hand drop dan under hand lob (M. Furqon, 2002:28). Sesuai dengan sistem energi yang dibutuhkan dalam bulutangkis unsur yangpaling dominan adalah power, khususnya power lengan dan tungkai. Hal initerlihat saat gerakan memukul shuttlecock, terutama saat melakukan smash,dimana smash membutuhkan unsur power lengan yang baik.

Latihan fisik pada setiap cabang olahraga merupakan pondasi utama dalampembinaan teknik, taktik serta mental selanjutnya. Semua komponen biomotorharus dapat dikembangkan untuk menunjang prestasi atlet. Dengan modal fisikyang prima tentunya atlet akan dapat menguasai tahap latihan selanjutnya. Persepsi Kinestetik merupakan suatu unsur diantara unsur-unsur kemampuanbiomotorik, yang dapat ditingkatkan sampai batas-batas tertentu denganmelakukan latihan-latihan tertentu yang sesuai. Persepsi Kinestetik ialah kombinasi darikecepatan maksimal dan ketepatan maksimal. Persepsi Kinestetik ini harus ditunjukkan oleh perasaan tubuh, atau benda melintasi udara dimana otot-otot harusmengeluarkan kekuatan dengan kecepatan yang tinggi agar dapat membawa tubuhatau obyek pada saat pelaksanaan gerak untuk dapat mencapai suatu jarak ketepatan. 


\section{KAJIAN TEORI}

\section{Teknik Dasar Bulu Tangkis}

\section{a. Pengertian Teknik Dasar}

Teknik dasar dalam olahraga adalah kemampuan dalam melaksanakan gerakan-gerakan yang ada dalam suatu cabang olahraga dengan tepat, tepat dan cermat. Sedangkan MF.Siregar yang dikutip oleh Suharno HP.(1978:38) mengemukakan bahwa,'Teknik ialah pelaksanaan suatu kegiatan secara efektif dan rasional, yang memungkinkan tercapainya hasil-hasil yang baik di dalam pertandingan".Dengan demikian dapat juga dikatakan bahwa teknik merupakan pelaksanaan suatu metode gerakan atau kegiatan secara efektif dan rasional yang memungkinkan tercapainya hasil yang maksimal dalam perlombaan atau pertandingan.

Suharno HP. (1985:42) menyatakan bahwa, "teknik adalah suatu proses gerakan dan pembuktian dalam praktik sebaik mungkin untuk menyelesaikan tugas yang pasti dalam cabang olahraga”. jadi teknik dasar bermain sepak takraw merupakan keterampilan dan kecakapan seseorang untuk bergerak secara efektif dan dengan suatu tujuan. Hal ini merupakan dasar bagi atlet atau pemain untuk mencapai prestasi setinggi-tingginya, di samping faktor lain seperti kondisi fisik, taktik, dan mental yang baik.

Teknik dasar merupakan dasar dari suatu penguasaan keterampilan. Daya tarik dari pertandingan bulutangkis terletak pada segi penguasaan teknik yang diterapkan oleh kedua regu yang bertanding. Wiel Coerver (1987 : 19), mengemukakan bahwa pentingnya penguasaan teknik :

Tidak ada cabang olahraga lain yang menghendaki penguasaan teknik yang begitu banyak seperti bulutangkis. Situasi yang dihadapi senantiasa berubah, sedang lawan harus ditanggulangi mungkin seorang, tetapi dapat juga lebih. Penguasaan teknik yang baik merupakan persyaratan agar dapat ditanggulangi berbagai situasi dalam permainan bulutangkis dengan sikap mantap.

Penguasaan keterampilan teknik dasar bermain bulutangkis dan didukung oleh kondisi fisik yang baik, merupakan syarat yang harus dipenuhi oleh setiap pemain. Seorang pemain bulutangkis dikatakan terampil, jika 
mampu melakukan teknik-teknik dasar bermain dengan baik dan benar tanpa gerakan yang berlebihan.

Lapangan bulu tangkis berbentuk persegi panjang dan mempunyai ukuran seperti terlihat pada gambar halaman 10. Garis-garis yang ada mempunyai ketebalan $40 \mathrm{~mm}$ dan harus berwarna kontras terhadap warna lapangan. Warna yang disarankan untuk garis adalah putih atau kuning. Permukaan lapangan disarankan terbuat dari kayu atau bahan sintetis yg lunak. Permukaan lapangan yang terbuat dari beton atau bahan sintetik yang keras sangat tidak dianjurkan karena dapat mengakibatkan cedera pada pemain.

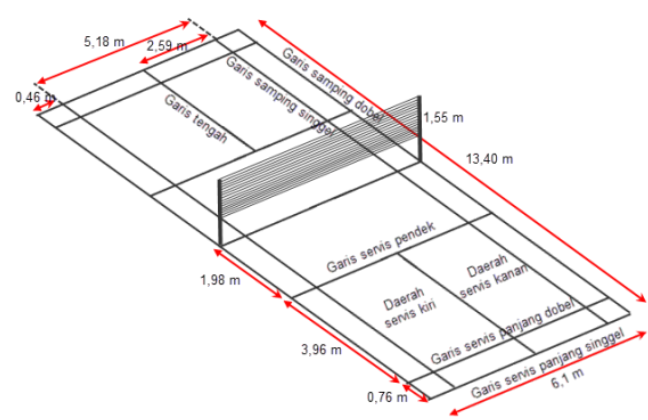

(Gambar 1. Lapangan Bulu Tangkis)

https://arproductionsblog.blogspot.com/2018/11/gambar-lapangan-bulu-tangkisbeserta.html

\section{b. Macam Teknik Dasar Bulutangkis}

Cara Memegang Raket : Ada 2 cara pegangan raket yaitu : Short Service dan Backhand.

Pegangan raket cara Short Service

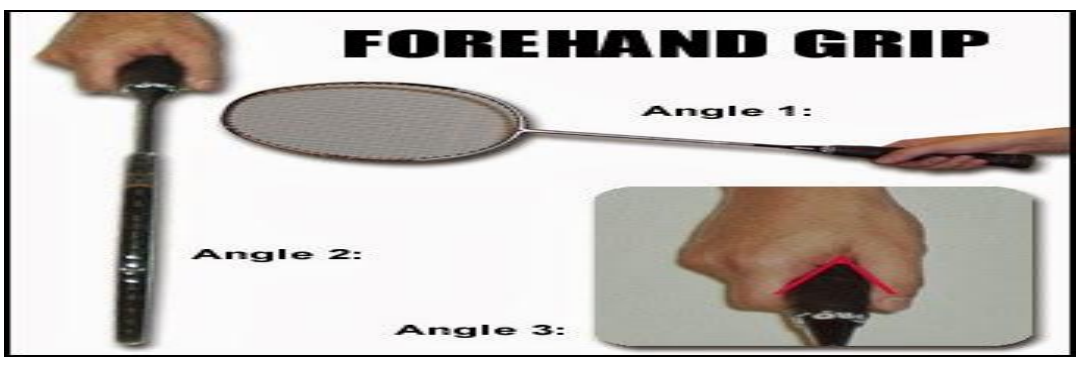

(Gambar 2. Pegangan raket Forehand) https://perpustakaan.id/cara-memegang-raket/

Pegang raket dengan tangan kiri, kepala raket menyamping, pegang raket seperti menjabat tangan ( bentuk V ) pada gagang raket. Jari tengah, jari 
HUBUNGAN ANTARA KOORDINASI MATA-TANGAN, PERSEPSI KINESTETIK DAN KEKUATAN

OTOT PERUT DENGAN KEMAMPUAN SHORT SERVICE DALAM PERMAINAN BULUTANGKIS

PADA PEMAIN PUTRA USIA 14-15 TAHUN PB NATURA PRAMBANAN KLATEN TAHUN 2019

(Iwan Arya Kusuma)

manis, dan kelingking menggenggam raket sedangkan jari telunjuk agak terpisah. Letakan ibu jari diantara tiga jari dan jari telunjuk

Pegangan raket cara backhand

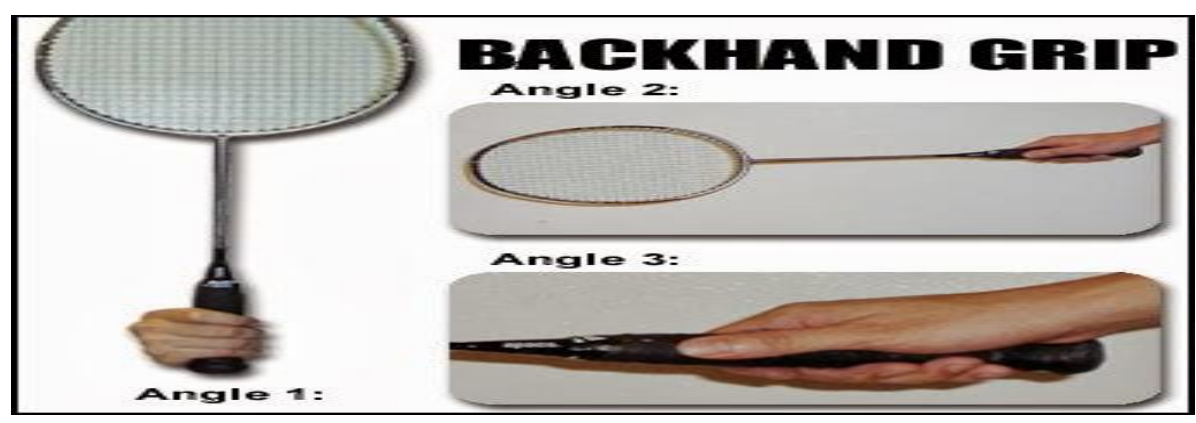

(Gambar 3. Pegangan raket Backhand)

https://perpustakaan.id/cara-memegang-raket/

Geser V tangah kearah dalam. Letaknya disamping dalam, bantalan jempol berada pada pegangan raket yang lebar.

1) Gerakan kaki ( footwork )

Kecepatan gerak kaki untuk bisa menghasilkan pukulan yang berkualitas. Gerak langkah ke depan, belakang, samping saat memukul kok dengan memperhatikan keseimbangan. Gerak langkah meluncur cepat sangat efektif dalam memukul da hindari berdiri dengan telapak kaki saat menunggu datangnya kok

2) Sikap dan Posisi

Berat badan tetap bertumpu pada kedua kaki agar seimbang. Tekuk kedua lutut dan berdiri dengan ujung kaki sehingga posisi pinggang tetap tegak. Kedua kaki terbuka selebar bahu dengan posisi sejajar atau salah satu didepannya. Lengan dengan siku bengkok di samping badan sehingga lengan bagian atas yang memegang raket bebas bergerak. Kepala raket lebih tinggi dari kepala kita.

3) Hitting Position ( posisi memukul )

Overhead ( atas ) untuk right handed adalah posisi badan menyamping dengan arah net. Posisi kaki kanan di belakang kaki kiri. Saat memukul harus terjadi eprpindahan berat badan dari kaki kanan ke kaki kiri. Posisi badan harus dibelakang shutle kok yang akan dipukul. Untuk 
underhead posisi kaki kanan selalu di depan dan kaki kiri dibelakang. Lutut kanan dibengkokkan, kerendahannya sesuai dengan ketinggian shutle kok yang akan dipukul. Footwork maju mundur.

4) Service

Service short / service pendek : kok dipukul dengan ayunan raket yang relative pendek dan tidak menggunakan tenaga pergelangan tangan.

Service Short Service tinggi : kok dipukul dengan tenaga penuh, kedua kaki terbuka selebar pinggul. Dilakukan dengan sempurna serta diikuti gerak peralihan titik berat badan dari kaki belakang ke kaki depan secara continue. Biasanya digunakan pemain tunggal.Service backhand : kai kanan di depan kaki kiri, ujung kaki kanan mengarah ke sasaran yang diinginkan. Titik berat badan di kedua kaki. Ayunan raket relatif pendek hanya didorong peralihan berat badan dari kai belakang ke depan.

5) Pengembalian service

Teknik pengembalian servis, sangat penting dikuasai dengan benar oleh setiap pemain bulutangkis. Arahkan kok ke daerah sisi kanan dan kiri lapangan lawan atau ke sudut depan atau belakang lapangan lawan.

6) Underhand

Saat memukul kok, gunakan tenaga kekuatan siku dan pergelangan tangan, hingga gerakan lanjut dari pukulan ini berakhir di atas bahu kiri. Perhatikan, agar telapak kaki kanan tetap kontak dengan lantai sambil menjangkau kok ada dua jenis yaitu clear underhand dan flick underhand.

7) Overhead clear/ lob

Pegangan Short Service, pegang raket pada posisinya disamping bahu. Posisi kaki kanan di belakang kaki kiri, saat memukul terjadi perpindahan beban badan. Posisi badan dibelakang shutle kok. Shutle kok dipukul seperti gerakan melempar. Saat perkenaan tangan harus lurus. Lecutkan pergelangan saat terkena shutle kok. 
8) Smash

Yaitu pukulan overhead (atas) yang diarahkan ke bawah dan dilakukan dengan tenaga penuh. Pukulan ini identik sebagai pukulan menyerang. Karena itu tujuan utamanya untuk mematikan lawan.

9) Dropshot ( pukulan potong )

Adalah pukulan yang dilakukan seperti smes. Perbedaannya pada posisi raket saat perkenaan dengan kok. Shutle kok dipukul dengan dorongan dan sentuhan yang halus. Dropshot (pukulan potong) yang baik adalah apabila jatuhnya shutle kok dekat dengan net dan tidak melewati garis ganda.

10) Netting

Adalah pukulan yang dilakukan dekat net, diarahkan sedekat mungkin ke net, dipukul dengan sentuhan tenaga halus sekali. Pukulan netting yang baik yaitu apabila shutle koknya dipukul halus dan melintir tipis dekat sekali dengan net.

\section{Koordinai Mata Tangan}

\section{a. Koordinais mata tangan}

Koordinasi merupakan salah satu komponen kondisi fisik yang di dalamnya terdiri dari beberapa komponen kondisi fisik yang saling berkaitan satu dengan lainnya. Beroperansinya koordinasi dalam kegiatan olahraga selalu melibatkan unsur kondisi fisik lainnya seperti kecepatan, kekuatan daya tahan dan fleksibilitas. Jika unsur-unsur kondisi fisik seperti kecepatan, kekuatan, daya tahan dan fleksibilitas baik, maka akan sangat mendukung kualitas atau kemampuan koordinasi.

Koordinasi pada dasarnya merupakan kemampuan seseorang untuk merangkaikan beberapa gerakan menjadi satu pola gerakan yang efektif dan efisien. Berkaitan dengan koordinasi Rusli Lutan dan Adang Suherman (2000: 172) menyatakan, "Koordinasi merupakan keharmonisan kerja antara kelompok otot selama melakukan tugas gerak yang menunjukkan tingkat keterampilan". Menurut M. Sajoto (1995: 9) koordinasi adalah, "Kemampuan 
seseorang mengintegrasikan bermacam-macam gerakan yang berbeda ke dalam pola gerakan tunggal secara efektif”. Menurut Ismaryati (2006: 53-54) bahwa, "Koordinasi merupakan hubungan yang harmonis dari hubungan saling berpengaruh di antara kelompok-kelompok otot selama melakukan kerja, yang ditunjukkan dengan tingkat keterampilan. Sedangkan Brian J. Sharkey (2003: 169) menyatakan, "Koordinasi mengimplikasikan hubungan yang harmonis, penyatuan atau aliran gerak yang halus dalam melakukan pekerjaan”.

Berdasarkan pengertian koordinasi yang dikemukakan empat ahli tersebut dapat disimpulkan, koordinasi merupakan kemampuan seseorang untuk merangkaikan beberapa gerakan menjadi satu pola gerakan yang efektif dan efisien. Bertolak pengertian koordinasi tersebut dapat dirumuskan pengertian koordinasi mata-tangan yaitu, kemampuan seseorang untuk mengintegrasikan rangsangan yang diterima melalui mata dan tangan sebagai fungsi penggerak utama untuk melakukan gerakan yang halus dan efisien sesuai rangsangan yang diterima. Hal ini sesuai pengertian koordiansi matatangan yang dikemukakan Sadoso Sumosardjuno (1994: 125) bahwa, "Koordinasi mata-tangan adalah suatu integrasi antara mata sebagai pemegang fungsi utama, dan tangan sebagai pemegang fungsi yang melakukan suatu gerakan tertentu".

Keberadaan koordinasi mata-tangan sangat berperan penting dalam permainan bulu tangkis, karena seluruh permainan bulu tangkis dibutuhkan kecermatan pandangan dan keakuratan pukulan. Untuk membuat pukulan tenis yang baik, maka setiap pemain bulu tangkis harus cermat mengantisipasi datangnya shutle kok, dan dengan segera melakukan pukulan dengan benar dan mengarahkan pukulannya pada sasaran yang diinginkan. Tanpa memiliki kecermatan pandangan saat mengamati atau mengantisipasi datangnya shutle kok dari lawan, maka pukulan backhand tidak dapat dilakukan dengan baik. 
HUBUNGAN ANTARA KOORDINASI MATA-TANGAN, PERSEPSI KINESTETIK DAN KEKUATAN OTOT PERUT DENGAN KEMAMPUAN SHORT SERVICE DALAM PERMAINAN BULUTANGKIS PADA PEMAIN PUTRA USIA 14-15 TAHUN PB NATURA PRAMBANAN KLATEN TAHUN 2019 (Iwan Arya Kusuma)

\section{HASIL PENELITIAN DAN PEMBAHASAN}

\section{Hasil Penelitian}

Data yang diperoleh dari tiap-tiap variabel tersebut kemudian dikelompokkan dan dianalisis dengan statistik, seperti terlihat pada lampiran. Adapun rangkuman deskripsi data secara keseluruhan akan disajikan sebagai berikut:

Tabel 2.Deskripsi Data Hasil Tes Koordinasi mata-tangan, Persepsi kinestetik dan Kekuatan Otot Perut dan Kemampuan Short Service .

\begin{tabular}{|c|c|c|c|c|c|c|}
\hline Variabel & Tes & $\mathrm{N}$ & Mean & SD & $\begin{array}{c}\text { Nilai } \\
\text { Tertinggi }\end{array}$ & $\begin{array}{c}\text { Nilai } \\
\text { Terendah }\end{array}$ \\
\hline \multirow{2}{*}{$\begin{array}{c}\text { Koordinasi mata- } \\
\text { tangan }\end{array}$} & Test & 30 & 13.50 & 2.03 & 16 & 9 \\
\cline { 2 - 7 } Re-test & 30 & 15.30 & 1.93 & 18 & 11 \\
\hline \multirow{2}{*}{ Persepsi kinestetik } & Test & 30 & 3.83 & 1.72 & 7 & 1 \\
\cline { 2 - 7 } & Re-test & 30 & 3.12 & 1.73 & 6 & 0 \\
\hline \multirow{2}{*}{ Kekuatan Otot Perut } & Test & 30 & 19.00 & 2.61 & 23 & 15 \\
\cline { 2 - 7 } & Re-test & 30 & 20.73 & 2.39 & 25 & 16 \\
\hline \multirow{2}{*}{ Kemampuan Short } & Test & 30 & 16.03 & 4.85 & 26 & 9 \\
\cline { 2 - 7 } Service & Re-test & 30 & 15.43 & 3.61 & 22 & 8 \\
\hline
\end{tabular}

\section{Pembahasan}

\section{a. Hubungan Antara Power otot tungkai dengan Ketrampilan Smash}

Dari hasil analisis korelasi pada dataPower otot tungkai dengan Ketrampilan Smash, diperoleh nilai r sebesar 0.429, dimana nilai tersebut lebih besar dari nilai $r_{\text {tabel }}$ pada taraf signifikansi $5 \%$ yaitu 0,361 . Karena nilai $r_{\text {hitung }}>$ $\mathrm{r}_{\text {tabel}}$, maka nilai korelasi signifikan.Hal ini berarti bahwaperubahan variansi Ketrampilan Smash dipengaruhi oleh komponen variansi Power otot tungkai.

\section{b. Hubungan Antara Power otot lengan dengan Ketrampilan Smash}

Berdasarkan hasil analisis yang telah dilakukan terhadap data Power otot lengan terhadap Ketrampilan Smash, diperoleh nilai r sebesar 0.410, dimana nilai tersebut lebih besar dari nilai $r_{\text {tabel }}$ pada taraf signifikansi $5 \%$ yaitu 0,361 . Karenanilai $r_{\text {hitung }}>r_{\text {tabel }}$, maka nilai korelasi signifikan.Hal ini berarti bahwa 
variansi unsur Power otot lengan berpengaruh terhadap peningkatan variansi Ketrampilan Smash.

\section{c. Hubungan Antara Koordinasi mata tangan dengan Ketrampilan Smash}

Berdasarkan hasil analisis yang telah dilakukan terhadap data Koordinasi mata tanganterhadap Passing atas, diperoleh nilai $\mathrm{r}$ sebesar 0.400, dimana nilai tersebut lebih besar dari nilai $r_{\text {tabel }}$ pada taraf signifikansi $5 \%$ yaitu 0,361. Karenanilai $r_{\text {hitung }}>r_{\text {tabel }}$, maka nilai korelasi signifikan.Dengan demikian dapat disimpulkan bahwa Koordinasi mata tangan memiliki hubungan yang signifikan terhadap Ketrampilan Smash.

\section{d. Hubungan Power otot tungkai, Power otot lengandan Koordinasi mata tangan dengan Ketrampilan Smash}

Pada Hipotesis dinyatakan bahwa hubungan antara Power otot tungkai, Power otot lengandan Koordinasi mata tangan dengan Ketrampilan Smash di ketahui $\mathrm{R}_{\mathrm{y}(123)}^{2}=0.442$ sedangkan $\mathrm{r}_{\text {tabel }}$ pada taraf signifikasi 0,05 dan $\mathrm{n}=30 \mathrm{di}$

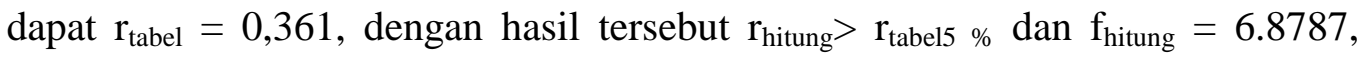
sedangkan $\mathrm{f}_{\text {tabel5\% }}$ dengan db 3:26 $=2,89$, ini berarti $\mathrm{F}_{0}>\mathrm{F}_{\text {tabel5\% }}$ Maka hipotesis di terima.

\section{KESIMPULAN DAN SARAN}

\section{Simpulan}

Berdasarkan hasil penelitian dan hasil analisis regresi dan korelasi product moment yang telah dilaksanakan dapat diperoleh simpulan sebagai berikut:

a. Ada hubungan yang signifikan antara Koordinasi mata-tangan dengan Kemampuan Short Service, $\mathrm{r}_{\text {hitung }}=0,426>\mathrm{r}_{\text {tabel }} \%=0,361$.

b. Ada hubungan yang signifikan antara Persepsi kinestetik dengan Kemampuan Short Service, $\mathrm{r}_{\text {hitung }}=0,414>\mathrm{r}_{\text {tabel }} \%=0,361$.

c. Ada hubungan yang signifikan antara Kekuatan Otot Perut dengan Kemampuan Short Service termasuk data inversi karena lebih kecil dari $\mathrm{r}$ tabel, $\mathrm{r}_{\text {hitung }}=0,458<$ $\mathrm{r}_{\text {tabel } 5 \%}=0,361$. 
HUBUNGAN ANTARA KOORDINASI MATA-TANGAN, PERSEPSI KINESTETIK DAN KEKUATAN

OTOT PERUT DENGAN KEMAMPUAN SHORT SERVICE DALAM PERMAINAN BULUTANGKIS

PADA PEMAIN PUTRA USIA 14-15 TAHUN PB NATURA PRAMBANAN KLATEN TAHUN 2019

(Iwan Arya Kusuma)

d. Ada hubungan yang signifikan antara Koordinasi mata-tangan, Persepsi kinestetik dan Kekuatan Otot Perut dengan Kemampuan Short Service, $\mathrm{R}_{\mathrm{y}(123)}^{2}$ sebesar 0.452

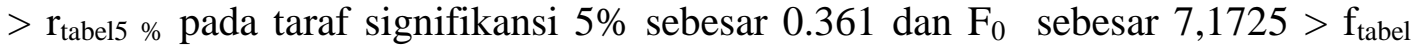
pada taraf signifikansi $5 \%$ sebesar 2,89 .

\section{Saran}

Sehubungan dengan simpulan yang telah diambil, maka kepada Pelatih, khususnya di PersatuanBulutangkis, disarankan agar:

a. Dalam upaya untuk meningkatkan Kemampuan Short Service hendaknya memberikan latihan Koordinasi mata-tangan, Persepsi kinestetik dan Kekuatan Otot Perut.

b. Latihan fisik yang diberikan harus proporsional. Besarnya porsi latihan untuk tiap unsur Koordinasi mata-tangan, Persepsi kinestetik dan Kekuatan Otot Perut disesuaikan dengan besarnya nilai hubungan tiap variabel terhadap Kemampuan Short Service.

\section{Daftar Pustaka}

Harsono, 1988. Coaching dan aspek-aspek Psikologi dalam Coaching. Jakarta: Ditjen Dikti.

Herman Subardjah. 2008. Permainan Bulutangkis. Solo: CV "Setia Aji” Surakarta.

Ismaryati. 2008. Tes dan Pengukuran Olahraga. Surakarta: Sebelas Maret University Press.

Poole, J. 1982. Belajar Bulutangkis. Bandung: PIONIR.

Johnson, B.L. dan Nelson, J.K. 1986. Practical Measurements for Evaluation in Physical Education. New York: Macmillan Publishing Company.

Kirkendall, D.R., Gruber, J.J., and Johnson, R.E. 1987. Measurement and Evaluation for Physical Educators. Illinois: Human Kinetics Publishers, Inc.

M. Furqon Hidayatullah. 2002. Pembinaan Olahraga Usia Dini. Surakarta: UNS. Pemanduan Bakat Panahan. Jakarta:Direktorat KeolahragaanDitjend Diklusipora Departemen Pendidikan dan Kebudayaan. 
HUBUNGAN ANTARA KOORDINASI MATA-TANGAN, PERSEPSI KINESTETIK DAN KEKUATAN

OTOT PERUT DENGAN KEMAMPUAN SHORT SERVICE DALAM PERMAINAN BULUTANGKIS

PADA PEMAIN PUTRA USIA 14-15 TAHUN PB NATURA PRAMBANAN KLATEN TAHUN 2019

(Iwan Arya Kusuma)

M. Sajoto. 1995. Pembinaan dan Peningkatan Kondisi Fisik. Semarang: Dahara Prize.

Muhajir. 2004. Pendidikan Jasmani Teori dan Praktek. Jakarta: Erlangga.

Mulyono, B 2008. Tes dan Pengukuran Pendidikan Jasmani/Olahraga. Surakarta: LPP UNS dan UNS Press.

Nurhasan. 2001.Tes dan Pengukuran Dalam Pendidikan Jasmani.Jakarta: Depdikbud.

Pudjianto dkk. 1978.Dasar Bermain Bulutangkis. Klaten: Intan.

Sajoto.1988.Pembinaan Fisik dalamOlahraga. Jakarta: P2LPTK.

Soekatamsi. 2001. Permainan Shutle kok I. Jakarta: Pusat Penerbitan Universitas Terbuka.

Sugiyanto dan Sudjarwo.1992.Perkembangan dan Belajar Gerak.Jakarta: Departemen Pendidikan dan Kebudayaan.

Sudjarwo. 1992. Ilmu Kepelatihan Dasar. Surakarta: Depdikbud RI Universitas Sebelas Maret.

Suharno HP. 1983. Ilmu Coaching Umum. Yogyakarta: Yayasan STO.

Tohar. 1991. Bulu Tangkis. Bandung:FPOK IKIP Bandung.

Winarno Surakhmad. 1982. Penelitian Ilmiah Dasar Metode Teknik. Jakarta: Tarsito. 